\title{
Can Personality Explain the Educational Gradient in Divorce? Evidence From a Nationally Representative Panel Survey
}

\section{Diederik Boertien', Christian von Scheve', and Mona Park ${ }^{3}$}

\begin{abstract}
The social demographic literature on divorce suggests that the lower educated are more likely to have personality traits that reduce relationship stability. However, few empirical verifications of this proposition exist. To fill this void, we look at the distribution of personality traits across educational groups of married individuals in Britain. Using data from the British Household Panel Survey $(N=2,665)$, we first estimated the effects of the "Big Five" personality traits agreeableness, conscientiousness, extraversion, neuroticism, and openness to experience on divorce and subsequently examine their distribution across educational groups. We find that in particular women's personality traits differ by education. We also observe that personality traits affecting divorce risk are distributed unevenly over educational groups, but they do not favor the higher educated in general. In sum, the data do not support the hypothesis that the lower educated in Britain have personality traits that reduce relationship stability.
\end{abstract}

'European University Institute, Florence, Italy

${ }^{2}$ Freie Universität Berlin, Berlin, Germany

${ }^{3}$ Ludwig-Maximilians-Universität München, München, Germany

\section{Corresponding Author:}

Diederik Boertien, Department of Political and Social Sciences, European University Institute, Via dei Roccettini 9, I-500I4 San Domenico di Fiesole (FI), Italy.

Email: diederik.boertien@eui.eu 


\section{Keywords}

divorce, family, inequality, personality, social stratification, education

Personality traits have been central within social psychological research on divorce (Claxton, O’Rourke, Smith, \& DeLongis, 2012; Donnellan, Conger, \& Bryant, 2004; Heaven, Smith, Prabhakar, Abraham, \& Mete, 2006; Karney \& Bradbury, 1995; Kurdek, 1993; Noftle \& Shaver, 2006; Roberts, Kuncel, Shiner, Caspi, \& Goldberg, 2007; Robins, Caspi, \& Moffitt, 2000; White, Hendrick, \& Hendrick, 2004). However, most studies draw on relatively small and selective samples, making representative investigations on the links between personality and divorce comparably rare. More recently, measures of psychological dispositions have been incorporated in nationally representative surveys such as the British Household Panel Survey (BHPS) and the German Socio-Economic Panel Study and led to novel insights on the effects of personality on divorce (Blazys, 2009; Lundberg, 2010; Solomon \& Jackson, 2014). But, these studies have not yet accounted for various social science propositions regarding structural predictors of divorce risk and how they might interact with psychological factors. In this respect, a frequently made proposition is that in particular the lower educated are more likely to have interactions and communication patterns within relationships that are detrimental to marital quality and stability (Amato \& Rogers, 1997; Härkönen \& Dronkers, 2006; Jalovaara, 2013; Matysiak, Marta, \& Vignoli, 2013). Differences in personality are mentioned as possible sources of such patterns (Bracher, Santow, Morgan, \& Trussell, 1993; Conger, Conger, \& Martin, 2010; Jalovaara, 2001).

In this contribution, we seek to test this claim that has previously not been investigated empirically. We attend to the question whether the lower educated, in general, have social-psychological traits that are detrimental to relationship stability and thus increase their risk of divorce compared with others. In particular, we investigate this question by focusing on the distribution of several socially important personality traits (the "Big Five" personality traits Agreeableness, Conscientiousness, Extraversion, Neuroticism, and Openness to Experience) across educational groups in Britain, and how they account for differences in relationship stability. We hypothesize that the lower educated, compared with the higher educated, score higher on personality traits that are related to increased divorce risk. Using data on married individuals from the BHPS, we first estimate the effects of personality traits on divorce and subsequently look at their distribution across educational groups and whether they contribute to a higher probability of divorce for the lower educated. Our overall aim is to contribute to an understanding of how variables 
influencing relationship dynamics are distributed across educational groups by applying the study of personality to issues related to social demographic research.

\section{Education, Personality, and Divorce}

Social demographic studies on divorce have speculated about the reasons why in many societies today the lower educated divorce more than the higher educated (Amato, 2010; Härkönen \& Dronkers, 2006). One of the reasons proposed in the literature is that lower educated individuals have, on average, poorer quality interactions with their partners (Amato \& Rogers, 1997; Bracher et al., 1993; Conger et al., 2010; Härkönen \& Dronkers, 2006; Jalovaara, 2001, 2013; Matysiak et al., 2013; Teachman, 2002). At the same time, only few empirical tests of this proposition exist and most studies on interactions within relationships do not focus on educational differences (Amato, 1996; Donnellan et al., 2004). An exception is a study by Amato and Rogers (1997) who investigated whether marital problems mediated the influence of demographic factors on divorce. They found that higher education is related to lower levels of jealousy and substance abuse, higher levels of infidelity, but not to moodiness, irritating habits, or the foolish spending of money. However, it remains an open question whether such behavior is cause or consequence of low relationship quality.

Psychological research has demonstrated how personality traits structure interactions in relationships and influences the ability to deal with relationship problems (Heaven et al., 2006; Huston \& Houts, 1998; Karney \& Bradbury, 1995). Given that personality traits are more stable over time and less influenced by context than specific marital problems, studying them could give a better indication of whether the lower educated are more likely to have stable traits that affect divorce risk through interactions within relationships. Although several authors have suggested that personality traits mediate the link between education and marital quality (Conger et al., 2010) or stability (Bracher et al., 1993; Jalovaara, 2001; Teachman, 2002), they have not yet tested this claim empirically.

Whereas the effects of personality traits on divorce have been studied in several studies over the past decades (Karney \& Bradbury, 1995; Kurdek, 1993; Roberts et al., 2007), it has only been in recent years that scholars have started to use large and nationally representative data sets (Blazys, 2009; Lundberg, 2010; Solomon \& Jackson, 2014). Associations between marital stability and personality have been documented for most of the commonly used models of personality in both large-scale representative studies as well as in earlier research. This has particularly been the case for the "Big Five," 
the most widely used taxonomy of personality traits in psychological research. According to this taxonomy, five very general personality traits cover the wide spectrum of identified dispositions: agreeableness, extraversion, conscientiousness, neuroticism, and openness to experience (see Costa, Herbst, \& McCrae, 2000; Funder, 2001). In general, overviews of research on the issue concluded that neuroticism, extraversion, and openness to experience increase divorce risk, and that agreeableness and conscientiousness decrease it (Karney \& Bradbury, 1995; Roberts et al., 2007). However, the results for agreeableness and extraversion were not confirmed in more recent and nationally representative studies (Lundberg, 2010; Solomon \& Jackson, 2014).

What could be the mechanisms connecting personality and divorce risk? In psychology research, it is commonly assumed that personality traits affect relationship stability through their influence on relationship quality (Solomon \& Jackson, 2014). Many studies have looked at the relationship between personality and marital satisfaction (Claxton et al., 2012; Heaven et al., 2006; Noftle \& Shaver, 2006; Robins et al., 2000; White et al., 2004), and have shown that these effects are indeed mediating personality effects on divorce (Solomon \& Jackson, 2014).

Neuroticism has been shown to reduce relationship quality through detrimental communication patterns (Caughlin, Huston, \& Hours, 2000). The remaining four traits are often hypothesized as positively affecting marital satisfaction. While extraversion is assumed to be related to positive emotions, agreeableness and conscientiousness are expected to lead to better problemsolving abilities (Donnellan et al., 2004; Heaven et al., 2006). Openness to experience is supposed to promote a more intellectual approach to problem solving (Claxton et al., 2012; Donnellan et al., 2004; Heaven et al., 2006). The empirical evidence for these other four traits, however, is mixed. Donnellan et al. (2004) suggested that agreeableness, openness to experience (positive), and neuroticism (negative) are the most important predictors of marital satisfaction. However, Karney and Bradbury (1995) reported negative effects of openness to experience.

Even though marital satisfaction is an important predictor of divorce, there are also other factors that affect divorce risk (Levinger, 1965, 1976; Kurdek, 1993). Solomon and Jackson (2014) found that after controlling for marital satisfaction, the majority of the effects of personality traits remains to be explained in several cases. This is illustrated by sometimes opposing results found for marital satisfaction and stability. For instance, openness to experience is in some cases found to positively affect both marital satisfaction (Donnellan et al., 2004) and stability (Lundberg, 2010). Thus, it is plausible to assume that personality traits could also affect the other two components driving divorce decisions according to social exchange theory: barriers to divorce and alternatives to the relationship (Levinger, 1965, 1976). 
One can, for instance, hypothesize that traits related to more satisfying relationships render individuals more attractive to future partners and therefore increase divorce risk through increased alternatives available to the marriage. Botwin, Buss, and Shackelford (1997) showed that, on average, individuals exhibit a preference for partners who are agreeable and open to experience. Women, in particular, also look for partners who are extravert and conscientious. Other traits might increase the access to alternatives, such as extraversion, which is related to the ease of socializing and building social networks (Asendorpf \& Wilpers, 1998). Similarly, certain personality traits might affect the perceived attractiveness of being single or make people averse to change. While openness to experience is related to the readiness to make life changes and might lower the barriers to divorce (Whitbourne, 1986), neuroticism has been shown to be related to attachment anxiety (Noftle $\&$ Shaver, 2006), that is, the fear of being left by a partner, which most likely increases the barriers to divorce.

Personality can also affect selection into marriage. Openness to experience is related to lower probabilities of marriage by age 35 , whereas conscientiousness (for men), extraversion, agreeableness, and neuroticism (for women) increase the odds of marriage (Lundberg, 2010). Differences in divorce risk might be tied to the effect of personality on the initial selection of partners rather than exclusively to processes that occur after union formation. Similarly, age at marriage is a consistent predictor of divorce risk (Amato, 2010) and could be related to personality traits.

Taken together, some traits might increase marital satisfaction but are at the same time related to an increased risk of divorce by reducing the barriers to divorce and affecting the perception of alternatives to the relationship. Although the processes underlying these linkages are beyond the scope of this article, it seems fruitful to look into the moderating role of personality to better understand the relation between education and divorce on a general level. We have chosen education as the independent variable of interest due to the consequences of the negative correlation between education and divorce for levels of inequality in society (Härkönen \& Dronkers, 2006). At the same time, studying personality could provide insights into the mechanisms underlying correlations of frequently studied variables with divorce risk, for example, age at marriage and premarital cohabitation.

\section{Personality and Divorce in Britain}

The aim of this study is to use a large representative panel to investigate the distribution of personality traits that affect divorce risk across educational groups in Britain. The context of Britain differs from other countries in 
several respects. In general, levels of income inequality are higher than in other European countries and welfare support is in general means-tested and not as generous (Esping-Andersen, 1999). Despite its more liberal policy context, couple behavior in Britain is not yet as egalitarian as in some other European countries and the United States. Although few households operate according to a traditional division of labor, not many couples divide both paid and unpaid labor equally (Esping-Andersen, Boertien, Bonke, \& Gracia, 2013; Sullivan \& Gershuny, 2003). This reflects both lower levels of fulltime labor force participation by women and less participation in domestic work by men. The correlation between education and divorce in Britain is currently negative for both men and women (Chan \& Halpin, 2005).

What are the expected effects of the distribution of personality traits on the educational gradient in Britain? Using representative data for Germany, Lundberg (2010) shows that certain personality traits affect divorce risk. Openness to experience increases break-up chances for both men and women, whereas extraversion does so only for men. Conscientiousness increases union stability for men in Germany. Evidence based on representative data for Britain does not yet exist, but we expect personality to be related to divorce risk in Britain too based on the evidence for Germany and studies showing the effects of personality traits on marital satisfaction and divorce (Claxton et al., 2012; Heaven et al., 2006; Karney \& Bradbury, 1995; Noftle $\&$ Shaver, 2006; Roberts et al., 2007; Robins et al., 2000; White et al., 2004). Our first hypothesis therefore is that

\section{Hypothesis 1: Personality traits are related to divorce risk.}

A recent study has established differences in personality traits across educational groups in Germany (Dehne \& Schupp, 2007), although without testing the statistical significance of the findings. Based on these results and the proposition in the literature that the lower educated might have personality traits increasing the likelihood of divorce, we expect that

Hypothesis 2: Personality traits are related to education.

Hypothesis 3: The lower educated are more likely to possess personality traits that increase the likelihood of divorce, which can explain part of the educational gradient of divorce in Britain.

Specifically, based on the literature review, we expect scoring high on extraversion and neuroticism to be related to higher divorce risk and lower education, as well as scoring low on conscientiousness and agreeableness. Openness to experience is related to an intellectual approach of problem solving 
(Donnellan et al., 2004) and therefore likely related to higher education, but the trait has been found to increase divorce risk. We therefore expect it not to be a relevant mediator in our analysis.

\section{Data and Method}

We use data from the BHPS to estimate the effects of personality traits on the risk of divorce. The BHPS is a representative longitudinal household panel survey for the British population conducted between 1991 and 2009. The survey includes retrospective and prospective data on marital histories of respondents. Based on these data, we were able to construct a yearly data set that recorded whether respondents were still with their partners in the reference year (0) or not (1) since the first time they got married.

\section{Sample}

The BHPS measured personality traits in 2005 . We therefore selected all respondents surveyed in 2005 who had complete information on our dependent variable, that is, divorce. We dropped respondents who were never married until the last wave (2009) or did not provide information on their marital history. Given that the correlation between education and divorce is subject to changes over time (Härkönen \& Dronkers, 2006), our sample had to be relatively homogenous in terms of marriage cohorts. We therefore decided to only look at marriages contracted in the 1990s or the 2000s and dropped respondents from the analysis who got married earlier. All remaining individuals were used for the analysis. We used multiple imputation to prevent dropping cases due to missing values on other variables of the analysis. In 2005, 15,617 individuals participated in the BHPS. Of these individuals, $0.1 \%$ had no marital history information at all, $25.5 \%$ had no complete retrospective information on their first marriage (of which, $80 \%$ was older than 40 years in 2005), $26.0 \%$ never married, and $31.4 \%$ married before 1990 . This left us with a sample of 2,665 individuals who married for the first time in the 1990 s or the 2000 s.

The sample excludes respondents who cohabited but were not married at the time of interview. We only looked at married individuals to connect to the literature on educational differences in divorce (which is almost entirely based on studies of married individuals). In addition, cohabiting nonmarried unions might have different barriers to divorce, which could influence the relation between personality and divorce. This would require a separate investigation of cohabiting unions which could be interesting for future research. We also decided to only include first marriages to avoid overrepresentation of 
individuals who are more likely to divorce. Because earlier research found differences in the divorce effects of many variables by gender (e.g., personality traits, income, education, labor market status; Kalmijn \& Poortman, 2006; Lundberg, 2010; Sayer, England, Allison, \& Kangas, 2011), we analyzed one male and one female subsample.

After selecting the individuals for the study, we constructed yearly information on the dependent and independent variables. Using discrete-time event history models, we estimated whether divorce risk differed by scores on the personality trait measures. Personality was not always measured before the relationship started or before the divorce was observed. Given that personality traits are considered to be fairly stable during adulthood (CobbClark \& Schurer, 2012; Conley, 1985; McCrae \& Costa, 1990; Pedersen \& Reynolds, 1998), we treated them as time-invariant factors. However, more recent research showed that personality changes over the life course and following major life events (Costa et al., 2000; Jackson, Thoemmes, Jonkmann, Lüdtke, \& Trautwein, 2012; Specht, Egloff, \& Schmukle, 2011). Therefore, we conducted robustness checks to test whether our effects differ when only looking at cases in which personality was measured before divorce. Unless mentioned, this was not the case.

\section{Measures}

The dependent variable of the analysis was divorce in the year of reference. The main independent variables were education and personality. We used two measures of education, a categorical measure reflecting lower (International Standard Classification of Education, ISCED Categories 1-2), middle (ISCED 3-4), and higher education (ISCED 5-6), and a continuous measure reflecting the years of education. We primarily report results for the continuous measure because of the better model fit. However, we also computed the main analysis using the categorical measure and report any deviations from the continuous outcome in the results section.

We operationalized and measured personality using a short-scale version of the Big Five Inventory (John, Donahue, \& Kentle, 1991), an established and well-validated (e.g., Srivastava, John, Gosling, \& Potter, 2003) measure based on the Five Factor Model of personality encompassing openness to experience, extraversion, neuroticism, conscientiousness, and agreeableness. This model is a taxonomy of personality traits covering the broad spectrum of specific personality traits on an abstract level (John \& Srivastava, 1999). The short scale included in the BHPS in 2005 assessed the Big Five dimensions using three items for each dimension, answered on 7-point scales ranging from do not agree at all to fully agree (Dehne \& Schupp, 2007; Gerlitz 
$\&$ Schupp, 2005). The reliability of the resulting scales ranged from $\alpha=.52$, for agreeableness to $\alpha=.70$, for neuroticism. See Table A1 in Appendix A, for more detailed information. The relatively low reliability scores are due to each question measuring one subcomponent of a general personality trait and because Cronbach's alpha usually depends on the number of items in a scale (Cortina, 1993). Each question therefore does not measure the exact same part of the trait, hence, the low resulting reliability. To test whether joining the different questions into scales affected our results, we reran the main analysis using each question separately instead. Results did not differ from using the composite measures.

We used the following control variables for the analysis: duration of the marriage, duration squared, employment status (dummy for being employed), number of children, whether a person lived with both biological parents until age 16, whether the couple lived together before marrying, and the calendar year to which the information refer. Education and the control variables were measured at $t-1$, whereas the independent variable (having experienced a divorce in the past year) was measured at $t=0$. See Table 1 , for descriptive statistics of the sample.

\section{Procedure}

The analysis consisted of two stages. First, we examined the association between education and personality traits by running sets of ordinary least squares regressions. For each personality trait, we ran a regression with the trait as the dependent and education as the independent variable. We looked at the relationship between education and personality using one wave per person (i.e., 2005, when personality was measured in the BHPS). Controls included were duration, duration squared, and calendar year. The aim of these models was descriptively assessing the relation between education and personality. Subsequently, we estimated discrete-time event history models with divorce as the dependent variable. We examined whether the different personality traits were associated to divorce risk. In the next step, we looked at the correlation between education and divorce, and to what extent this effect gets mediated when including personality traits. To determine whether personality traits significantly mediated the relation between education and divorce, we used a significance test based on standardizing the logit coefficients of the effect of education on the mediating variable (taken from a model with the mediating variable as the dependent variable) and the effect of the mediating variable on divorce, controlling for education (see Iacobucci, 2012). 
Table I. Descriptive Statistics for the Sample Used in This Article.

\begin{tabular}{lccccc}
\hline & $M$ & $S D$ & Minimum & Maximum & \% Missing \\
\hline Male (I)/female (0) & 0.48 & & 0 & 1 & 0 \\
Education (years) & 13.8 & 2.2 & 9 & 17 & 7.1 \\
Agreeableness & 0 & 0.9 & -3.7 & 1.5 & 7.4 \\
Conscientiousness & 22.0 & 13.85 & 0 & 68 & 7.4 \\
Extraversion & 13.4 & 3.1 & 4 & 18 & 7.4 \\
Neuroticism & 2.81 & 0.98 & 0 & 5.58 & 7.2 \\
Openness to experience & 1.41 & 1.00 & 0 & 4.21 & 7.5 \\
Calendar year & 2003 & 4.5 & 1991 & 2009 & 0 \\
Duration & 5.43 & 4.21 & 0.04 & 19 & 0 \\
Age at marriage & 30.0 & 7.77 & 17 & 83 & 0 \\
Employed & 0.61 & 0.49 & 0 & 1 & 0 \\
Number of children & 1.14 & 1.06 & 0 & 6 & 0 \\
Parental divorce & 0.19 & & 0 & 1 & 4.9 \\
Cohabitation before marriage & 0.62 & & 0 & 1 & 0 \\
Divorce (yearly hazard) & 0.016 & & 0 & 1 & 0 \\
Marriage year & 1997.9 & 4.76 & 1990 & 2009 & 0 \\
$N$ & $2,665(20,524$ & person-years) & \\
\hline
\end{tabular}

In a final step, we successively added control variables to the analysis to look at the possible mechanisms underlying our findings. We also added interaction effects of personality traits with duration and education to account for possible heterogeneity in effects of personality. We used multiple imputation of missing values on the independent variables for the entire analysis. See Table 1, for details on the extent to which values were imputed for each variable, $17.8 \%$ of cases had missing information on at least one variable. As a robustness check and to ease interpretation of our findings, all main results were also replicated using linear probability models (LPMs) presented in Appendix A.

\section{Results}

Table 2 shows the relationship between personality traits and education for men and women. The first observation is that many personality traits are related to education in Britain. However, personality seems much more related to education for women than for men. Openness to experience is strongly and positively related to education for both men and women. Agreeableness (negative), conscientiousness (positive), extraversion (positive), and neuroticism (negative) are all related to education, too, but just for women. This is an observation we will discuss later. 
Table 2. Coefficients Taken from Separate Ordinary Least Squares Regressions Explaining Education by Each Personality Trait and Gender.

\begin{tabular}{lccccc}
\hline & \multicolumn{2}{c}{ Men } & & \multicolumn{2}{c}{ Women } \\
\cline { 2 - 3 } \cline { 5 - 6 } & \multicolumn{2}{c}{ Education } & & & \multicolumn{2}{c}{ Education } \\
\cline { 2 - 3 } \cline { 5 - 6 } & Coefficient & $S E$ & & Coefficient & $S E$ \\
\hline Agreeableness & .03 & .07 & & $-.15^{*}$ & .08 \\
Conscientiousness & -.08 & .08 & & $.17^{* *}$ & .08 \\
Extraversion & -.06 & .07 & & $.17^{* *}$ & .07 \\
Neuroticism & -.05 & .07 & & $-.18^{* * *}$ & .07 \\
Openness to experience & $.54^{* * * *}$ & .08 & & $.59^{* * *}$ & .07 \\
$N$ & 1,262 & & & 1,403 & \\
\hline
\end{tabular}

Note. Separate ordinary least squares regressions ran for each personality trait, control variables included duration, duration squared, and calendar year.

$*_{p}<.10 .{ }^{*} p<.05 . * * * p<.01$.

Tables 3 and 4 show how education, personality, and controls are associated to divorce risk for men and women (see Tables A1 and A2 in Appendix A for LPMs). From Model 1, we can observe that both higher educated men and women who married after 1990 were significantly less likely to divorce than lower educated individuals. In Model 2, we observe the relationship between personality and divorce. For both men and women, several personality traits significantly predict divorce risk. Conscientiousness is negatively related to divorce and extraversion is positively related to it. For men, also openness to experience stabilized relationships significantly.

For women, conscientiousness and extraversion are positively related to education, too, but given that extraversion destabilizes relationships this trait is unlikely to explain the educational gradient in divorce. When adding education to the analysis in Model 3, we see that the educational gradient for women indeed did not change compared with Model 1. This suggests that, overall, personality traits cannot explain the correlation between education and divorce for women. We checked whether conscientiousness and the other traits significantly mediated the effect of education on divorce individually, but this was not the case for any of them (the $z$ score for conscientiousness mediating the effect of education is -1.24 ).

For men, only openness to experience stabilizes their relationships and is strongly and positively related to education. When adding education to the analysis in Model 3, the coefficient for education becomes slightly lower than 


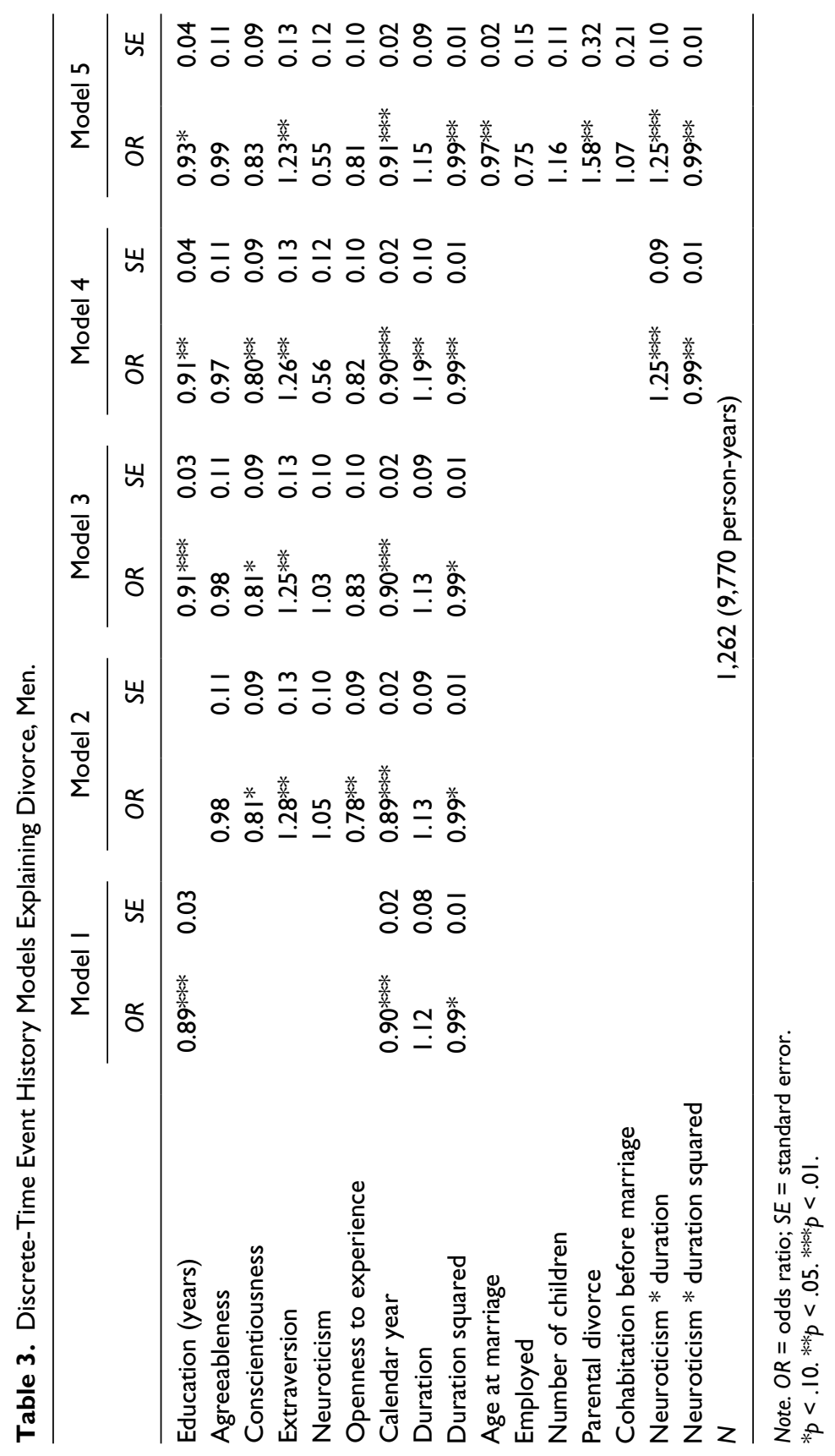




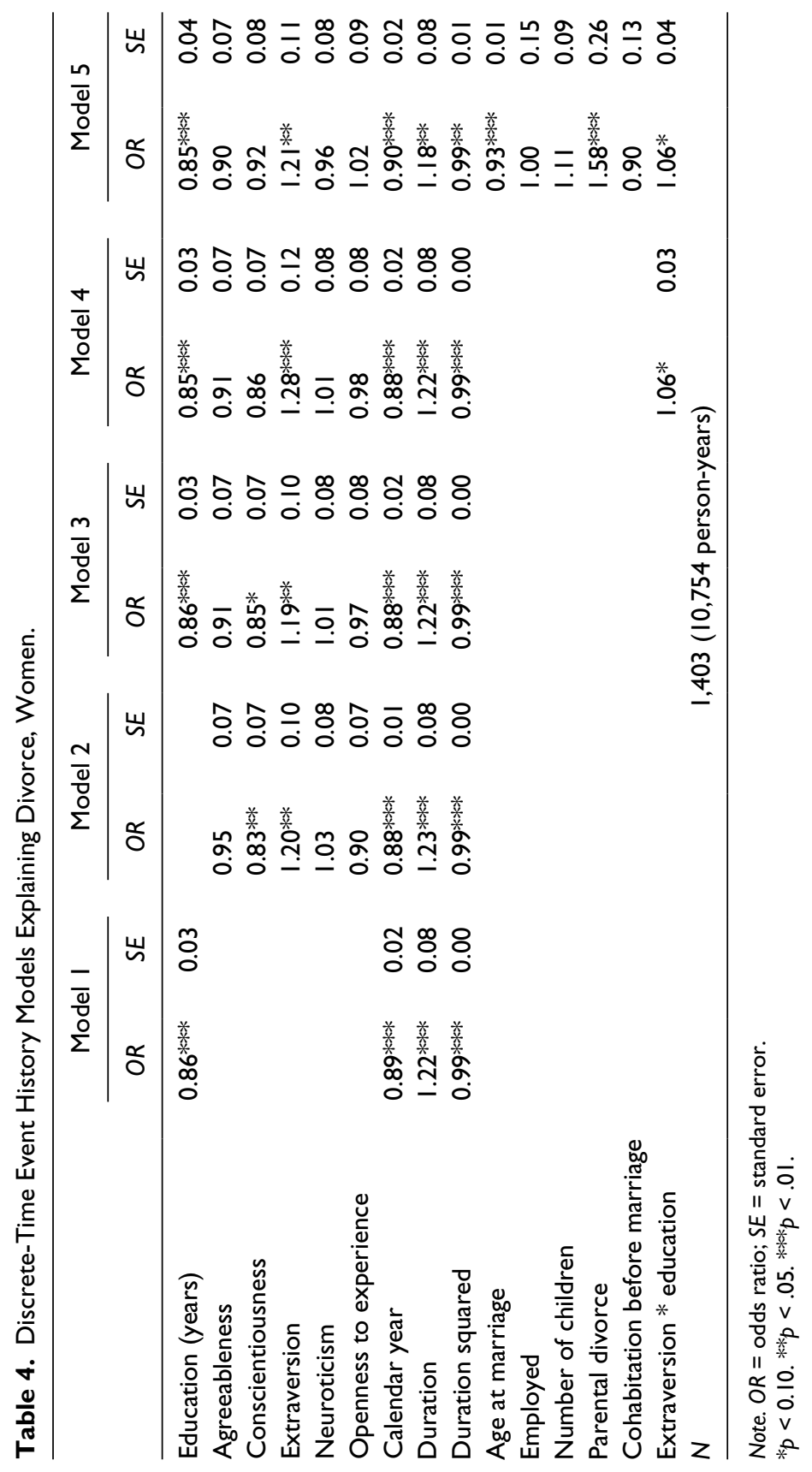


in Model 1 (also in the LPM shown in Appendix A, Table A1, which suggested that personality traits explain around $13 \%$ of the effect of education). However, none of the personality traits significantly mediates the effect of education on divorce on its own (the $z$ score for openness to experience is -1.34 , results not shown). We also tested whether all personality traits taken together significantly mediated the effect of education using the $k h b$ program in STATA (Kohler, Karlson, \& Holm, 2011) on the nonimputed data ( $k h b$ is not applicable to data with multiple imputation). The analysis shows that personality traits explain the effects of education on a marginally significant level ( $p$ value, .07, results not shown).

The effects of personality could differ by education or duration of the marriage. To fully account for possible mediating effects of education, we therefore also tested whether interactions of personality with duration and education should be included in the models. To that aim, we ran separate models for each interaction effect by gender. Education and personality were centered at the average values, whereas for duration the value 0 corresponds to the start of the marriage. Two interaction effects turned out to be statistically significant (the other interaction effects were not only statistically insignificant but also did not influence the coefficient for education much). The effect of neuroticism for men seems initially not detrimental to relationship stability, but effects become significantly more positive at later durations. Extraversion appears to destabilize marriages more for higher educated women. We included the statistically significant interaction effects in Models 4 of Tables 3 and 4, but the coefficients of education remained stable (and slightly increased for women). The same counts for the mediation analysis with the statistical significance of the mediating effect of personality overall dropping to a $p$ value of .09 for men. Overall, there seems to be little support for the proposition that the lower educated possess personality traits that are detrimental to the stability of marriages.

In a last step, we added variables to the analysis that could be mechanisms underlying the relationship between personality and divorce (Model 5). Results show that some of these effects remained while others became smaller. For women, the effects of conscientiousness and extraversion on divorce can partly be explained by the controls we included. Additional analysis (not shown) suggested that age at marriage was almost entirely responsible for these reductions. Individuals who marry at younger ages are more likely to divorce. Extravert respondents are significantly more likely to marry at younger ages, whereas conscientious people tend to wait longer until they marry. The $z$ scores for these mediating effects are 1.90 and 2.37, respectively. 
Summarizing, the results provide some support for our Hypothesis $1-$ conscientiousness, extraversion, and openness to experience predict divorce risk, whereas agreeableness and neuroticism do not. In addition, the effects for openness to experience and conscientiousness become statistically insignificant once including additional variables. However, future research can look at whether these are actually mediators (for instance, personality traits might affect divorce risk by influencing age at marriage) of the effects of personality on education. The results support Hypothesis 2 that personality traits are unevenly distributed across educational groups. However, we find very little support for Hypothesis 3 that the lower educated possess more personality traits that are detrimental to relationship stability. Only for men did personality explain a small part of the effect of education on divorce, and only in some specifications this mediating effect was marginally statistically significant.

We performed a set of robustness checks to reduce the risk that our results are rooted in the analytical strategies we employed. First, we used a categorical measure of education instead of a continuous indicator. While some effects of personality traits on divorce became more significant, they also did not mediate the effect of education in a statistically significant way in these models. Second, we only looked at divorces that took place from 2005 onward, which is the year in which personality was assessed in the BHPS. Results of these analyses were very similar. A few coefficients became statistically insignificant due to the large reduction in sample size, but the size of the coefficients did not change notably. The only exception is neuroticism which became a significant and positive predictor of divorce for men. Similar to our previous results, personality traits only explained a small part of the educational gradient for men at most.

\section{Discussion}

The results of our study show that some personality traits matter for union stability, that personality traits are unevenly distributed across educational groups, and that they do not seem to favor the higher educated overall. For women, some personality traits contribute to a larger negative educational gradient in divorce (extraversion), whereas others reduce its size (conscientiousness), but none of these effects was significant. For men, the educational gradient is slightly explained by personality traits; mostly due to the positive correlation of education with openness to experience. However, the mediating effect was only significant in few specifications. Studies on education and divorce suggest that the lower educated are more likely to possess personality 
traits that are detrimental to union stability (Bracher et al., 1993; Conger et al., 2010; Jalovaara, 2001). To our knowledge, we are the first to directly test this assumption by using measures of personality traits from representative panel data. However, we do not find support for this assumption. Personality traits, generally, do not put the lower educated at a disadvantage compared with others when looking at union stability.

We find that many personality traits are unevenly distributed across educational groups, and especially so for women. Studying personality traits can therefore provide additional insights into the sources of inequality in society. Particularly, the differences in correlations between education and personality between men and women are remarkable. While openness to experience (related to creativity and critical thinking) is associated with education for both men and women, only higher educated women are less agreeable and neuroticistic, and more conscientious and extravert. This is, to our knowledge, a new result given that studies on personality and educational performance generally did not split up results by gender (Busato, Prins, Elshout, \& Hamaker, 2000; Farsides \& Woodfield, 2003). A possible explanation could be the higher anxiety experienced by women once taking standardized tests due to notions that men outperform women in such tests (Buchmann, DiPrete, \& McDaniel, 2008; Steele, 1997). Certain personality traits (e.g., neuroticism) might exacerbate these patterns. Personality could also affect fertility and marriage decisions which influence educational careers of women to a larger extent (Goldin, 2006). Future research could look into this finding further.

Given that personality traits seem to explain at most a small part of the negative correlation between education and divorce, which other alternative explanations remain? First of all, there are more personal traits that structure relationships. Other stable traits that influence interactions within relationships not accounted for in this study should therefore be investigated before we can conclude that the lower educated are not prone to have worse interactions in relationships due to inherent traits. Alternative explanations for the educational gradient in divorce could be that other socioeconomic factors related to low education reduce the quality of relationships through economic pressures for the lower educated. It could also be that the lower educated have lower barriers to divorce (Härkönen \& Dronkers, 2006).

We made some interesting observations regarding the general effects of personality traits on divorce. An earlier study using German panel data (Lundberg, 2010) found that openness to experience destabilizes marriages for both men and women. In the case of Britain, the opposite seems to be 
partly the case, that is, openness to experience is related to lower divorce risk for men, but not for women. This suggests that the effects of personality and divorce are not stable across contexts. Future research should look at cross-national and cross-temporal variation. Openness to experience could be related to barriers to divorce given that the trait is associated with the willingness to make changes in life (Whitbourne, 1986) and might therefore differ in relevance depending on how high barriers to divorce are in a given society.

In the German study of Lundberg (2010), conscientiousness is associated with lower and extraversion to higher divorce risk for men. The same pattern emerges from our study, although for men and women alike. Conscientiousness is linked to better problem-solving abilities (Donnellan et al., 2004; Heaven et al., 2006) and feeling obliged to keep up strong bonds with close friends and family (Asendorpf \& Wilpers, 1998). The consistent stabilizing effect of this trait could therefore reflect both increased marital satisfaction and higher barriers to divorce. Given that extraversion is normally expected to improve relationships (Donnellan et al., 2004; Heaven et al., 2006), the finding that it increases divorce risk is highly interesting. This might reflect extraverts' access to alternatives, given that the trait is related to ease of socializing and building social networks (Asendorpf \& Wilpers, 1998). However, our analysis suggests that almost half of the effect of extraversion for women can be explained by their lower age at marriage. Extraverts might therefore have a lower threshold to marry, which could lead to worse relationship outcomes. Future research should look at this proposition. In addition, the strong relation of age at marriage with personality suggests that personality traits might be an interesting factor to look at when explaining other demographic patterns.

\section{Conclusions}

Personality matters when it comes to the longevity of marriages. Extraversion is a trait related to decreased relationship duration, whereas conscientiousness and openness to experience (the latter only for men) increase the likelihood of people to stay together. Agreeableness and neuroticism, overall, seemed unrelated to divorce. Our aim was to test the claim made in research on divorce that the lower educated have more unfavorable personality traits when it comes to union stability relative to others (Bracher et al., 1993; Conger et al., 2010; Jalovaara, 2001). For Britain, we find that, overall, personality traits do not disadvantage the lower educated. While the lower 
educated do have some more unfavorable traits (e.g., low conscientiousness, low openness to experience, high neuroticism), these traits are not in principle associated with divorce risk. In addition, lower educated women were less extravert, which favors their relationship stability (although the mediating effect is not statistically significant). The results overall do not support the hypothesis that the lower educated have personality traits that increase divorce risk. Future research could investigate whether these results also hold when looking at other countries and different kinds of stable traits that affect interactions within relationships.

\section{Appendix A}

Measures Used for Personality Traits (2005), All Measured on I (Does Not Apply at All) to 7 (Does Apply) Likert-Type Scales

Agreeableness $(\alpha=.54)$

Am sometimes rude to others

Considerate and kind

Have a forgiving nature

Conscientiousness $(\alpha=.52)$

Do a thorough job

Do things efficiently

Tend to be lazy

Extraversion $(\alpha=.64)$

Am talkative

Reserved

Am outgoing, sociable

Neuroticism $(\alpha=.70)$

Worry a lot

Get nervous easily

Relaxed, handle stress well

Openness to experience $(\alpha=.64)$

Am original, come up with ideas

Value artistic, aesthetic experiences

Have an active imagination 


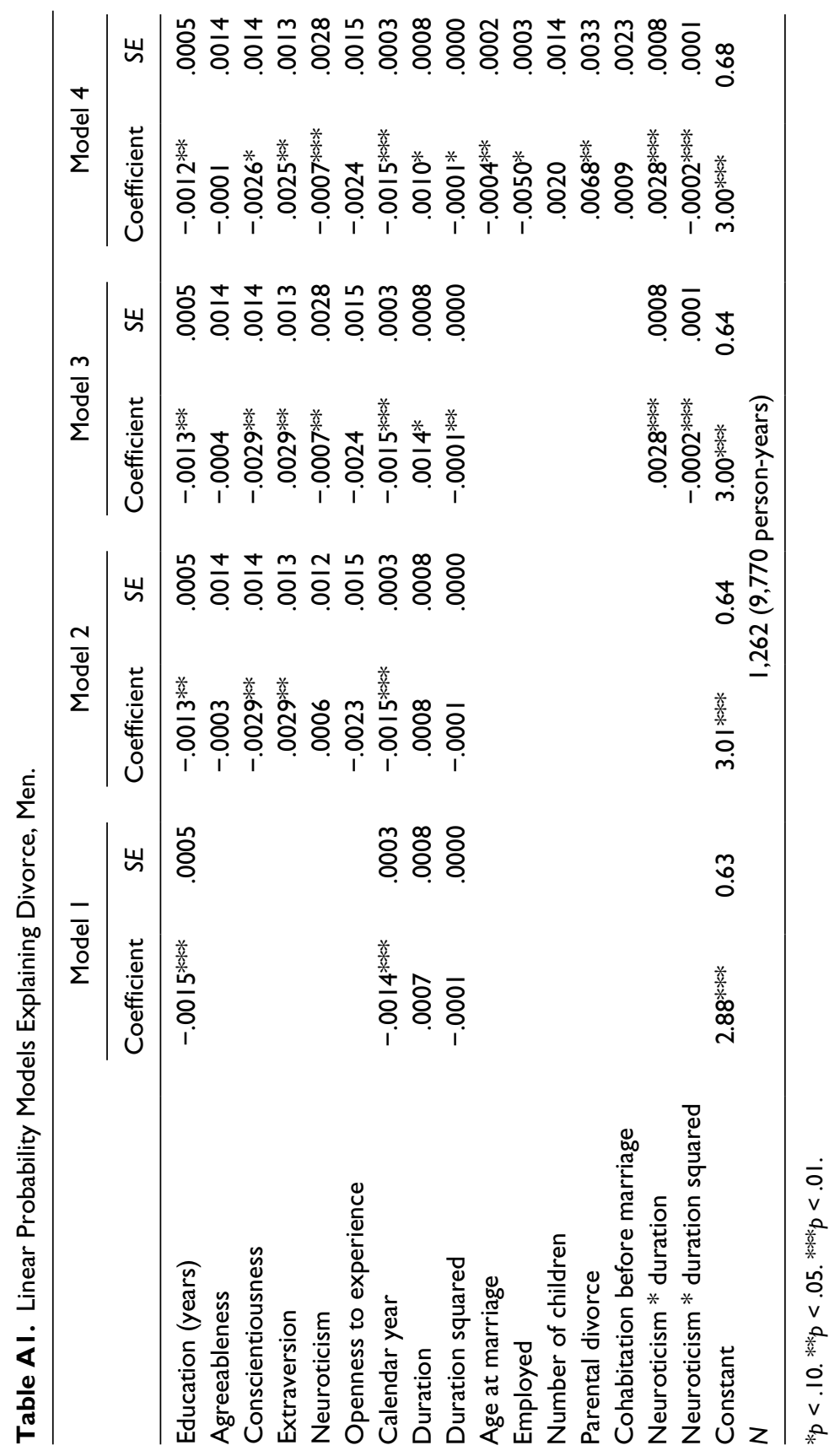




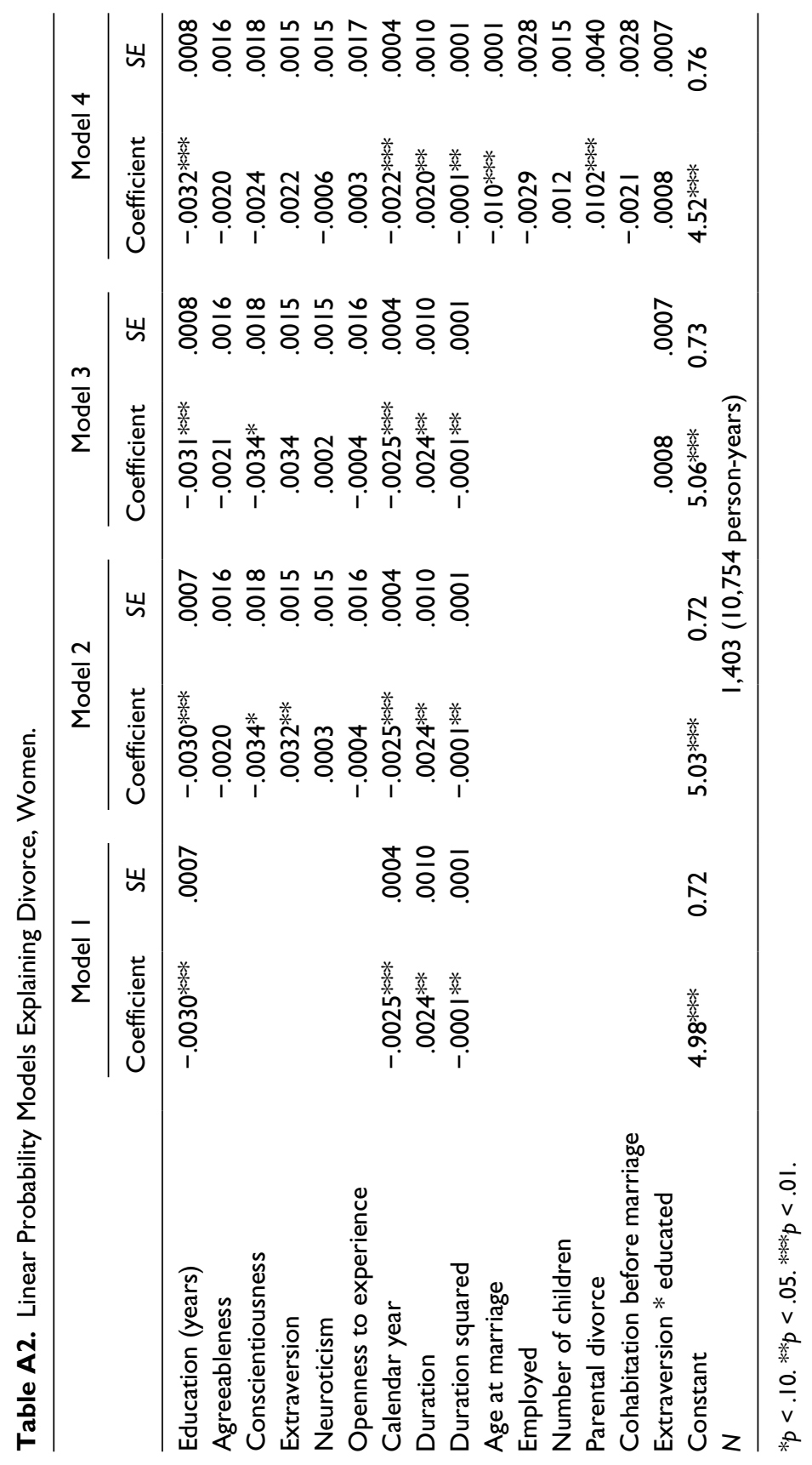




\section{Acknowledgment}

We thank Gabriel Bartl for assistance in data management and analysis.

\section{Declaration of Conflicting Interests}

The author(s) declared no potential conflicts of interest with respect to the research, authorship, and/or publication of this article.

\section{Funding}

The author(s) disclosed receipt of the following financial support for the research, authorship, and/or publication of this article: This work was in part supported by a grant of the Cluster of Excellence "Languages of Emotion" at Freie Universität Berlin to Christian von Scheve (Grant number: DFG-EXC 302 Project 412).

\section{References}

Amato, P. R. (1996). Explaining the intergenerational transmission of divorce. Journal of Marriage and the Family, 58, 628-640.

Amato, P. R. (2010). Research on divorce: Continuing trends and new developments. Journal of Marriage and Family, 72, 650-666.

Amato, P. R., \& Rogers, S. J. (1997). A longitudinal study of marital problems and subsequent divorce. Journal of Marriage and the Family, 59, 612-624.

Asendorpf, J. B., \& Wilpers, S. (1998). Personality effects on social relationships. Journal of Personality and Social Psychology, 74, 1531-1544.

Blazys, G. (2009). Personality, intelligence, and marital outcomes (Working Paper). Seattle: University of Washington.

Botwin, M. D., Buss, D. M., \& Shackelford, T. K. (1997). Personality and mate preferences: Five factors in mate selection and marital satisfaction. Journal of Personality, 65, 107-135.

Bracher, M., Santow, G., Morgan, S. P., \& Trussell, J. (1993). Marriage dissolution in Australia: Models and explanations. Population Studies, 47, 403-425.

Buchmann, C., DiPrete, T. A., \& McDaniel, A. (2008). Gender inequalities in education. Annual Review of Sociology, 34, 319-337.

Busato, V. V., Prins, F. J., Elshout, J. J., \& Hamaker, C. (2000). Intellectual ability, learning style, personality, achievement motivation and academic success of psychology students in higher education. Personality and Individual Differences, 29, 1057-1068.

Caughlin, J. P., Huston, T. L., \& Hours, R. M. (2000). How does personality matter in marriage? An examination of trait anxiety, interpersonal negativity, and marital satisfaction. Journal of Personality and Social Psychology, 78, 326-336.

Chan, T. W., \& Halpin, B. (2005). The instability of divorce risk factors in the UK (Working Paper). Oxford, England: University of Oxford.

Claxton, A., O’Rourke, A., Smith, J. Z., \& DeLongis, A. (2012). Personality traits and marital satisfaction within enduring relationships. Journal of Social and Personal Relationships, 29, 375-396. 
Cobb-Clark, D. A., \& Schurer, S. (2012). The stability of big-five personality traits. Economics Letters, 115, 11-15.

Conger, R. D., Conger, K. J., \& Martin, M. J. (2010). Socioeconomic status, family processes, and individual development. Journal of Marriage and Family, 72, 685-704.

Conley, J. J. (1985). Longitudinal stability of personality traits: A multitrait-multimethod-multioccasion analysis. Journal of Personality and Social Psychology, 49, 1266-1282.

Cortina, J. M. (1993). What is coefficient alpha? An examination of theory and applications. Journal of Applied Psychology, 78, 98-104.

Costa, P. T., Jr., Herbst, J. H., \& McCrae, R. R. (2000). Personality at midlife: Stability, intrinsic maturation, and response to life events. Assessment, 7, 365-378.

Dehne, M., \& Schupp, J. (2007). Persönlichkeitsmerkmale im Sozio-oekonomischen Panel (SOEP): Konzept, Umsetzung und empirische Eigenschaften (DIW Research Note 26) [Personality traits in the Socio-Economic Panel (SOEP): Concept, Measurement, and Findings]. Berlin, Germany: Deutsches Institut für Wirtschaftsforschung.

Donnellan, M. B., Conger, R. D., \& Bryant, C. M. (2004). The Big Five and enduring marriages. Journal of Research in Personality, 38, 481-504.

Esping-Andersen, G. (1999). The social foundations of postindustrial economies. Oxford, England: Oxford University Press.

Esping-Andersen, G., Boertien, D., Bonke, J., \& Gracia, P. (2013). Couple specialization in multiple equilibria. European Sociological Review, 29, 1280-1294.

Farsides, T., \& Woodfield, R. (2003). Individual differences and undergraduate academic success: The roles of personality, intelligence, and application. Personality and Individual Differences, 34, 1225-1243.

Funder, D. C. (2001). Personality. Annual Review of Psychology, 52, 197-221.

Gerlitz, J., \& Schupp, J. (2005). Zur Erhebung der Big-Five-basierten Persönlichkeitsmerkmale im SOEP [On measurement of the Big-Five personality traits in the SOEP] (DIW Research Notes 4). Berlin, Germany: Deutsches Institut für Wirtschaftsforschung.

Goldin, C. (2006). The quiet revolution that transformed women's employment, education, and family. American Economic Review, 96, 1-21.

Härkönen, J., \& Dronkers, J. (2006). Stability and change in the educational gradient of divorce: A comparison of seventeen countries. European Sociological Review, 22, 501-517.

Heaven, P. C. L., Smith, L., Prabhakar, S. M., Abraham, J., \& Mete, M. E. (2006). Personality and conflict communication patterns in cohabiting couples. Journal of Research in Personality, 40, 829-840.

Huston, T. L., \& Houts, R. M. (1998). The psychological infrastructure of courtship and marriage: The role of personality and compatibility in romantic relationships. In T. N. Bradbury (Ed.), The developmental course of marital dysfunction (pp. 114-151). New York, NY: Cambridge University Press.

Iacobucci, D. (2012). Mediation analysis and categorical variables: The final frontier. Journal of Consumer Psychology, 22, 582-594. 
Jackson, J. J., Thoemmes, F., Jonkmann, K., Lüdtke, O., \& Trautwein, U. (2012). Military training and personality trait development: Does the military make the man, or does the man make the military? Psychological Science, 23, 270-277.

Jalovaara, M. (2001). Socio-economic status and divorce in first marriages in Finland 1991-93. Population Studies, 55, 119-133.

Jalovaara, M. (2013). Socioeconomic resources and the dissolution of cohabitations and marriages. European Journal of Population, 29, 167-193.

John, O. P., Donahue, E. M., \& Kentle, R. L. (1991). The Big Five Inventory: Version $4 a$ and 54. Berkeley: University of California, Institute of Personality and Social Research.

John, O. P., \& Srivastava, S. (1999). The Big Five trait taxonomy: History, measurement, and theoretical perspectives. In L. A. Pervin \& O. P. John (Eds.), Handbook of personality: Theory and research (pp. 102-138). New York, NY: Guilford Press.

Kalmijn, M., \& Poortman, A. (2006). His or her divorce? The gendered nature of divorce and its determinants. European Sociological Review, 22, 201-214.

Karney, B., \& Bradbury, T. N. (1995). The longitudinal course of marital quality and stability. Psychological Bulletin, 118, 3-34.

Kohler, U., Karlson, K. B., \& Holm, A. (2011). Comparing coefficients of nested nonlinear probability models. Stata Journal, 11, 420-438.

Kurdek, L. A. (1993). Predicting marital dissolution: A 5-year prospective longitudinal study of newlywed couples. Journal of Personality and Social Psychology, 64, 221-242.

Levinger, G. (1965). Marital cohesiveness and dissolution: An integrative view. Journal of Marriage and the Family, 27, 19-28.

Levinger, G. (1976). A social psychological perspective on marital dissolution. Journal of Social Issues, 32, 21-47.

Lundberg, S. (2010). Personality and marital surplus (IZA Discussion Paper No. 4945). Retrieved from http://ftp.iza.org/dp4945.pdf

Matysiak, A., Marta, S., \& Vignoli, D. (2013). The changing educational gradient in marital disruption: A meta-analysis of European research findings. Population Studies, 68, 197-215.

McCrae, R. R., \& Costa, P. T. (1990). Personality in adulthood. New York, NY: Guildford Press.

Noftle, E. E., \& Shaver, P. R. (2006). Attachment dimensions and the big five personality traits: Associations and comparative ability to predict relationship quality. Journal of Research in Personality, 40, 179-208.

Pedersen, N. L., \& Reynolds, C. A. (1998). Stability and change in adult personality: Genetic and environmental components. European Journal of Personality, 12, 365-386.

Roberts, B. W., Kuncel, N. R., Shiner, R., Caspi, A., \& Goldberg, L. R. (2007). The power of personality: The comparative validity of personality traits, socioeconomic status, and cognitive ability for predicting important life outcomes. Perspectives on Psychological Science, 2, 313-345. 
Robins, R. W., Caspi, A., \& Moffitt, T. E. (2000). Two personalities, one relationship: Both partners' personality traits shape the quality of their relationship. Journal of Personality and Social Psychology, 79, 251-259.

Sayer, L. C., England, P., Allison, P. D., \& Kangas, N. (2011). She left, he left: How employment and satisfaction affect women's and men's decisions to leave marriages. American Journal of Sociology, 116, 1982-2018.

Solomon, B. C., \& Jackson, J. J. (2014). Why do personality traits predict divorce? Multiple pathways through satisfaction. Journal of Personality and Social Psychology, 106, 978-996.

Specht, J., Egloff, B., \& Schmukle, S. C. (2011). Stability and change of personality across the life course: The impact of age and major life events on meanlevel and rank-order stability of the Big Five. Journal of Personality and Social Psychology, 101, 862-882.

Srivastava, S., John, O. P., Gosling, S. D., \& Potter, J. (2003). Development of personality in early and middle adulthood: Set like plaster or persistent change? Journal of Personality and Social Psychology, 84, 1041-1053.

Steele, C. M. (1997). A threat in the air: How stereotypes shape intellectual ability and performance. American Psychologist, 52, 613-629.

Sullivan, O., \& Gershuny, J. (2003). Time use, gender, and public policy regimes. Social Politics, 10, 205-228.

Teachman, J. (2002). Stability across cohorts in divorce risk factors. Demography, $39,331-351$.

Whitbourne, S. K. (1986). Openness to experience, identity flexibility, and life change in adults. Journal of Personality and Social Psychology, 50, 163-168.

White, J. K., Hendrick, S. S., \& Hendrick, C. (2004). Big five personality variables and relationship constructs. Personality and Individual Differences, 37, 1519-1530. 